\title{
Diversidade genética de isolados de Ralstonia solanacearum e caracterização molecular quanto a filotipos e sequevares
}

\author{
Cassia Renata Pinheiro(1), Julie Anne Espíndola Amorim(2), Leandro Eugenio Cardamone Diniz(2), \\ Adriano Márcio Freire da Silva(2), Viviane Talamini( ${ }^{(2)}$ e Manoel Teixeira Souza Júnior ${ }^{(3)}$
}

\begin{abstract}
(1)Universidade Federal de Lavras, Caixa Postal 3.037, CEP 37200-000 Lavras, MG. E-mail: cassiapinheiro@gmail.com (2)Embrapa Tabuleiros Costeiros, Avenida Beira Mar, 3.250-B, Jardins, Caixa-Postal 44, CEP 49025-040 Aracaju, SE. E-mail: julie_anne@hotmail.com, leandro. diniz@cpatc.embrapa.br, adrianomfsilva@yahoo.com.br e viviane@cpatc.embrapa.br ${ }^{(3)}$ Embrapa Agroenergia, Parque Estação Biológica, Avenida W3 Norte Final, Asa Norte, CEP 70770-901 Brasília, DF. E-mail: manoel.souza@embrapa.br
\end{abstract}

Resumo - O objetivo deste trabalho foi identificar isolados brasileiros de Ralstonia solanacearum quanto a filotipos e sequevares, determinar sua diversidade genética, realizar a associação da estrutura genética do patógeno com sua classificação e origem geográfica e identificar um marcador molecular para a diagnose do moko-da-bananeira. Um grupo de 33 isolados de $R$. solanacearum, da coleção da Embrapa Tabuleiros Costeiros, coletado de diversos hospedeiros, foi caracterizado por meio de PCR em sequência palindrômica extragênica repetitiva (rep-PCR) e RAPD. Deste grupo, 19 perteciam à raça 2 do patógeno e 14 à raça 1, e 15 isolados eram associados à cultura da bananeira. Os filotipos e sequevares foram caracterizados e determinados por PCR Multiplex. Verificou-se que $82 \%$ dos isolados pertencem ao filotipo II, e $12 \%$ ao filotipo III. Todos os isolados da bananeira pertencem ao filotipo II. A técnica de RAPD foi eficiente em agrupar os isolados de acordo com sua origem geográfica; entretanto, ela requer um número elevado de marcas moleculares. Foi possível relacionar os isolados pela análise rep-PCR. O iniciador com sequências repetitivas enterobacterianas intergênicas de consenso (ERIC) possibilitou a separação dos isolados de acordo com a raça, e o iniciador REP permitiu a discriminação entre os filotipos. Estas duas análises foram as mais informativas.

Termos para indexação: Musa, marcador molecular, moko-da-bananeira, murcha bacteriana, rep-PCR, variabilidade genética.

\section{Genetic diversity of Ralstonia solanacearum isolates and molecular characterization as to phylotypes and sequevars}

\begin{abstract}
The objective of this work was to identify Brazilian isolates of Ralstonia solanacearum according to phylotypes and sequevars, to determine their genetic diversity, to associate the pathogen genetic structure with its taxonomy and geographical origin, and to identify a specific molecular marker to diagnose banana moko disease. A group of 33 isolates of $R$. solanacearum, from the collection of Embrapa Tabuleiros Costeiros, collected from different plant hosts, was characterized using the repetitive extragenic palindromic sequence-based PCR (rep-PCR) and RAPD. From this group, 19 belonged to the pathogen race 2 and 14 to the race 1, and 15 isolates were associated with banana crop. Phylotypes and sequevars were characterized and determined by Multiplex PCR. It was verified that the isolates belonged to phylotypes II (82\%) and III (12\%). All isolates from banana plants belonged to phylotype II. The RAPD technique was efficient in grouping these isolates according to their geographical origin; however, it requires a large number of molecular markers. It was possible to establish the relationships among the isolates by rep-PCR. The enterobacterial repetitive intergenic consensus primer (ERIC) made it possible to separate the isolates according to the race, and the REP primer allowed for the discrimination among phylotypes. These were the two most informative analyses.
\end{abstract}

Index terms: Musa, molecular marker, banana moko disease, bacterial wilt, rep-PCR, genetic variability.

\section{Introdução}

Ralstonia solanacearum é um dos mais importantes patógenos bacterianos do mundo, capaz de causar danos em cerca de 450 espécies de plantas pertencentes a mais de 54 famílias botânicas, entre as quais, culturas de alto valor econômico, como tomate, banana, batata, berinjela e pimentão (Xu et al., 2009).

Essa bactéria tem sido classificada, quanto ao fenótipo, em cinco raças, de acordo como a gama de 
hospedeiros (He et al., 1983; Hayward, 1994). Ela também é classificada em cinco biovares, com base na utilização de três açúcares (lactose, maltose e celobiose) e três álcoois (manitol, sorbitol e dulcitol) como fonte de carbono (Hayward, 1994). Porém, ambas as classificações, apesar de amplamente utilizadas por sua simplicidade e praticidade, não refletem a heterogeneidade dos isolados de $R$. solanacearum. Com o intuito de representar melhor essa variabilidade, Fegan \& Prior (2005), ao analisar as sequências da região espaçadora intergênica (ITS)16S-23S e dos genes egl, $h r p B$ e mutS, propuseram uma nova classificação hierárquica, subdividida em quatro níveis taxonômicos: espécie, filotipo, sequevar e clone.

A identificação da espécie pode ser facilmente realizada por meio de oligonucleotídeos iniciadores, como o OLI1/Y2, utilizado com sucesso para identificação de isolados de $R$. solanacearum e espécies relacionadas ( $R$. syzygii e Blood Disease Bacterium) (Seal et al., 1993; Arahal et al., 2004). Já os oligonucleotídeos PS96H/I são específicos para $R$. solanacearum (Seal et al., 1992); entretanto, o desconhecimento da região-alvo desse iniciador no genoma tem implicado em sua baixa utilização (Arahal et al., 2004).

Os filotipos são analisados de acordo com as variações de tamanho da sequência na região ITS. O filotipo está fortemente relacionado à origem geográfica do patógeno. Cada filotipo compreende um número de sequevares, grupo de isolados com uma sequência altamente conservada dentro da região sequenciada. A caracterização da estrutura e diversidade genética do patógeno é determinante para estudos de epidemiologia e orientação de programas de controle da doença, principalmente em estratégias que visam resistência específica a estirpes pertencentes a determinados locais. Alguns trabalhos (Salanobaut et al., 2002; Guidot et al., 2007; Coupat et al., 2008) levantam a hipótese de que $R$. solanacearum possa ter sua adaptação e evolução relacionados à capacidade de transferir genes horizontalmente, o que faz com que estirpes da mesma localidade tenham características geneticamente similares.

Diversos autores (Bringel et al., 2004; Silveira et al., 2005; Costa et al., 2007) têm direcionado seus estudos para a caracterização e diversidade de isolados de $R$. solanacearum em estados brasileiros. Entretanto, todos esses estudos focam a raça 1 do patógeno, não sendo registrado, até o momento, um estudo de caracterização da diversidade de isolados de $R$. solanacearum raça 2 coletados em regiões brasileiras.

O objetivo deste trabalho foi identificar, quanto a filotipos e sequevares, um grupo de isolados brasileiros de $R$. solanacearum, avaliar sua diversidade genética por meio de marcadores moleculares (RAPD e rep-PCR), associar grupos de isolados com sua classificação e origem geográfica e identificar um marcador molecular para a diagnose do moko-da-bananeira.

\section{Material e Métodos}

Foram utilizados 33 isolados de Ralstonia solanacearum, pertencentes à coleção biológica da Embrapa Tabuleiros Costeiros, dos quais 19 da raça 2 e 14 da raça 1 (Tabela 1). Os isolados foram cultivados por 24 horas em $4 \mathrm{~mL}$ de meio LB (Luria-Bertani) líquido (Sambrook \& Russel, 2001). Em seguida, $10 \mu \mathrm{L}$ foram transferidos para $1 \mathrm{~mL}$ de meio LB novo e mantidos em agitador orbital a $200 \mathrm{rpm}$, a $28^{\circ} \mathrm{C}$ por 24 horas. A suspensão bacteriana foi submetida à extração de DNA, com uso de um kit Wizard de extração e purificação de DNA genômico, (Promega Corporation, Madison, WI, EUA), de acordo com as instruções fornecidas pelo fabricante. O DNA obtido de cada isolado foi quantificado, e a concentração foi ajustada para $25 \mathrm{ng} \mu \mathrm{L}^{-1}$. O DNA genômico foi armazenado a $-20^{\circ} \mathrm{C}$ até o uso.

A confirmação da identificação dos isolados quanto à espécie $R$. solanacearum foi realizada mediante amplificação por PCR, tendo-se utilizado os oligonucleotídeos iniciadores específicos PS96H/I (Seal et al., 1992) e OLI1/Y2 (Seal et al., 1993). No presente estudo, foi realizada a análise conjunta dos dois pares de iniciadores, com o intuito de garantir maior confiabilidade na identificação dos isolados de R. solanacearum.

A técnica de PCR Multiplex foi aplicada para determinar os filotipos e as sequevares, tendo-se utilizado, respectivamente, os oligonucleotídeos iniciadores das séries Nmult e Mus, com as mesmas condições de amplificação descritas por Fegan \& Prior (2005).

Os produtos da amplificação foram separados em gel de agarose, corados em brometo de etídio $\left(0,5 \mu \mathrm{g} \mathrm{mL}^{-1}\right)$ 
e visualizados através de luz ultravioleta. O rep-PCR foi realizado com os oligonucleotídeos iniciadores correspondentes às três sequências repetitivas REP, ERIC e BOX. A PCR foi conduzida de acordo com o protocolo descrito por Horita \& Tsuchiya (2001).

Foram testados 61 oligonucleotídeos iniciadores RAPD, dos quais 27 (Tabela 2) foram selecionados por se apresentarem mais polimórficos e com melhor resolução em gel. As reações consistiram de um volume final de $25 \mu \mathrm{L}$, compostas por $0,5 \mu \mathrm{mol} \mathrm{L} \mathrm{L}^{-1}$ de oligonucleotídeo iniciador, $1 \mathrm{U}$ de Taq DNA polimerase (Promega), 0,2 mmol L-1 de cada dNTP, tampão de reação (1X), 1,5 mmol L-1 de $\mathrm{MgCl}_{2}, 50 \mathrm{ng}$ de DNA e água ultrapura para completar o volume da reação. Em todas as reações, foi incluído um controle negativo com água estéril. O programa de amplificação consistiu de uma desnaturação inicial a $96^{\circ} \mathrm{C}$ por 5 min, seguida por 35 ciclos de $94^{\circ} \mathrm{C}$ por $45 \mathrm{~s}, 36^{\circ} \mathrm{C}$ por $45 \mathrm{~s}, 72^{\circ} \mathrm{C}$ por $45 \mathrm{~s}$, e de um período de extensão final a $72^{\circ} \mathrm{C}$ por $10 \mathrm{~min}$.

Os produtos da amplificação foram separados em gel de agarose $(1,0 \%$ para o RAPD e $1,5 \%$ para rep-PCR), corados em brometo de etídio $(0,5 \mu \mathrm{g} \mathrm{mL}-1)$ e visualizados através de luz ultravioleta.

Tabela 1. Isolados de Ralstonia solanacearum estudados.

\begin{tabular}{|c|c|c|c|c|c|c|}
\hline Isolado & Hospedeiro & Origem & Procedência & Filotipo & Biovar & Raça \\
\hline TC01-01 & Musa sp. & IB-SBF & Humaitá, AM & II & I & 2 \\
\hline TC01-02 & Musa sp. & IB-SBF & Pará & II & $\mathrm{n}$ & 2 \\
\hline TC01-05 & Musa sp. & IB-SBF & Japoatã, SE & II & I & 2 \\
\hline TC01-06 & Musa sp. & IB-SBF & Humaitá, AM & II & $\mathrm{n}$ & 2 \\
\hline TC01-08 & Musa sp. & IB-SBF & Itacoara, AM & II & $\mathrm{n}$ & 2 \\
\hline ТC01-09 & Musa sp. & IB-SBF & Itacoara, AM & II & $\mathrm{n}$ & 2 \\
\hline TC01-17 & Musa sp. & IB-SBF & Japoatã, SE & II & I & 2 \\
\hline TC01-18 & Musa sp. & IB-SBF & Japoatã, SE & $\mathrm{n}$ & I & 2 \\
\hline TC01-25 & Musa sp. & IB-SBF & Tabatinga, AM & II & I & 2 \\
\hline TC01-26 & Musa sp. & IB-SBF & Japoatã, SE & II & I & 2 \\
\hline ТC01-29 & Musa sp. & CNPH & Amazonas & II & I & 2 \\
\hline TC01-42 & Musa sp. & MV & Canindé de São Francisco, SE & II & $\mathrm{n}$ & 2 \\
\hline TC01-43 & Musa sp. & MV & Canindé de São Francisco, SE & II & $\mathrm{n}$ & 2 \\
\hline TC01-44 & Musa sp. & MV & Cotinguiba Pindoba, SE & II & $\mathrm{n}$ & 2 \\
\hline TC01-45 & Musa sp. & MV & Cotinguiba Pindoba, SE & II & $\mathrm{n}$ & 2 \\
\hline TC02-01 & Heliconia sp. & IB-SBF & Abreu e Lima, PE & II & $\mathrm{n}$ & 2 \\
\hline TC02-02 & Heliconia sp. & IB-SBF & Abreu e Lima, PE & II & $\mathrm{n}$ & 2 \\
\hline TC02-03 & Heliconia sp. & IB-SBF & Abreu e Lima, PE & II & $\mathrm{n}$ & 2 \\
\hline TC02-04 & Heliconia sp. & Inpa & Coari, AM & $\mathrm{n}$ & I & 2 \\
\hline TC03-02 & Solanum lycopersicum & Inpa & Umaitá, AM & II & I & 1 \\
\hline TC03-03 & Solanum lycopersicum & Inpa & Manicore, AM & II & I & 1 \\
\hline TC03-04 & Solanum lycopersicum & CNPH & Guaraí, TO & III & III & 1 \\
\hline TC03-05 & Solanum lycopersicum & CNPH & Nova Friburgo, RJ & III & I & 1 \\
\hline TC03-06 & Solanum lycopersicum & CNPH & Domingo Martins, ES & II & I & 1 \\
\hline TC04-01 & Solanum melongena & Inpa & Benjamin Constant, AM & II & I & 1 \\
\hline TC04-02 & Solanum melongena & Inpa & Parintins, AM & II & I & 1 \\
\hline TC04-03 & Solanum melongena & CNPH & Gurupi, TO & III & III & 1 \\
\hline TC05-01 & Capsicum annuит & Inpa & Boca do Acre, AM & II & III & 1 \\
\hline TC05-02 & Capsicum annuиm & Inpa & Parintins, AM & II & I & 1 \\
\hline TC05-03 & Capsicum annuиm & CNPH & Camocin S. Felix, PE & III & III & 1 \\
\hline TC06-01 & Capsicum chinense & Inpa & Benjamin Constant, AM & II & III & 1 \\
\hline TC06-02 & Capsicum chinense & Inpa & Benjamin Constant, AM & II & III & 1 \\
\hline TC07-01 & Solanum tuberosum & CNPH & Pouso Alegre, $\mathrm{MG}$ & II & II & 1 \\
\hline
\end{tabular}

IB-SBF, Instituto Biológico, Secção de Bactérias Fitopatogênicas; Inpa, Instituto Nacional de Pesquisas da Amazônia; CNPH, Centro Nacional de Pesquisa de Hortaliças - Embrapa Hortaliças; MV, material vegetal; n, não identificado. 
A confirmação da identificação dos isolados, com uso dos oligonucleotídeos iniciadores PS96H/I e OLI1/ Y2, foi feita pela visualização de fragmentos de DNA amplificados, de tamanho esperado para cada par de oligonucleotídeos iniciadores. Dessa mesma forma, foi realizada a análise de identificação dos filotipos e sequevares.

Para os marcadores REP, ERIC, BOX e RAPD, foram construídas matrizes binárias a partir dos perfis de fragmentos gerados na amplificação. Atribuiu-se o valor (1) para a presença do fragmento e (0) para sua ausência. A partir dos dados binários, foi calculada a matriz de similaridade para os genótipos, tendo-se utilizado o coeficiente de similaridade de Jaccard. Com este coeficiente e com o método aglomerativo UPGMA ("unweighted pair group method with an arithmetic mean") (Sneath \& Sokal, 1973), foram realizadas as análises de agrupamento, e os valores de "bootstrap" (dez mil repetições) foram computados

Tabela 2. Sequência dos iniciadores RAPD utilizados.

\begin{tabular}{|c|c|}
\hline Iniciador & Sequência $\left(5^{\prime}-3^{\prime}\right)$ \\
\hline A 02 & TGC CGA GCT G \\
\hline A 03 & AGT CAG CCA C \\
\hline A 04 & AAT CGG GCT G \\
\hline A 09 & GGG TAA CGC C \\
\hline A 10 & GTG ATC GCA G \\
\hline A 11 & CAA TCG CCG T \\
\hline A 13 & CAG CAC CCA C \\
\hline A 14 & TCT GTG CTG G \\
\hline A 15 & TTC CGA ACC C \\
\hline A 16 & AGC CAG CGA A \\
\hline A 18 & AGG TGA CCG T \\
\hline A 19 & CAA ACG TCG G \\
\hline A 20 & GTT GCG ATC C \\
\hline B 11 & GTA GAC CCG T \\
\hline B 18 & CCA CAG CAG T \\
\hline $\mathrm{C} 02$ & GTG AGG CGT C \\
\hline F 01 & ACG GAT CCT G \\
\hline I 02 & GGA GGA GAG G \\
\hline K 20 & GTG TCG CGA G \\
\hline S 01 & CTA CTG GCG T \\
\hline S 18 & CTG GCG AAC T \\
\hline W 02 & ACC CCG CCAA \\
\hline W 04 & CAG AAG CGG A \\
\hline W 13 & CAC AGC GAC A \\
\hline W 19 & CAA AGC GCT C \\
\hline X 01 & CTG GGC ACG A \\
\hline X 03 & TGG CGC AGT G \\
\hline
\end{tabular}

pelos programas XLStat (Addinsoft, 2010) e Free Tree (Pavlícek et al., 1999).

\section{Resultados e Discussão}

Os DNAs obtidos dos 33 isolados, amplificados com os iniciadores OLI1/Y2 e PS96H/I, produziram fragmentos de 287 e $172 \mathrm{pb}$, respectivamente. Os perfis eletroforéticos das reações de PCR Multiplex revelaram a amplificação de um fragmento de $372 \mathrm{pb}$, em 27 dos isolados avaliados, e os caracterizaram como pertencentes ao filotipo II; outros quatro isolados apresentaram um fragmento de $91 \mathrm{pb}$ e se relacionaram com o filotipo III (Figura 1).

Todos os isolados pertencentes à raça 2 foram classificados no filotipo II, que está fortemente relacionado às Américas; entretanto, como observado por Cardozo et al. (2009), outros isolados provenientes de bananeiras oriundas da África e Ásia estão associados ao filotipo II, o que indica que ele pode estar mais relacionado ao moko-da-bananeira do que à distribuição geográfica global. Os isolados TC01-18 e TC02-04 não puderam ser relacionados a nenhum dos filotipos conhecidos.

O filotipo III é referido por conter isolados relacionados à África e ilhas próximas. Os quatro isolados positivos para o filotipo III pertencem à raça 1, e TC03-05 e TC03-04 foram isolados de tomateiro do Rio de Janeiro e Tocantins, respectivamente, o TC04-03 foi isolado de plantas de beringela de Tocantins, e o TC05-03 foi obtido de plantas de pimenta do Amazonas. Vários fatores podem ocasionar a presença deste filotipo em solo brasileiro, como falhas na fiscalização do trânsito de materiais vegetais ou introduções recentes.

A série Nmult foi capaz de distinguir três sequevares presentes em indivíduos pertencentes ao filotipo II, das Américas, definidos como sequevares 3, 4 e 6 (Prior $\&$ Fegan, 2005). No presente estudo, dos 27 isolados pertencentes ao filotipo II, cinco tiveram sua sequevar determinada como sequevar 6, pela amplificação de um fragmento de $220 \mathrm{pb}$ (Figura 2); destes cinco, três isolados pertencem à raça 2 e são patogênicos à helicônia (TC02-01, TC02-02 e TC02-03), e dois isolados são patogênicos à berinjela, raça 1 (TC04-01 e TC04-02). Com os demais 22 isolados não se obteve nenhuma amplificação, o que sugere a existência de outras sequevares relacionadas ao moko-da-bananeira. 


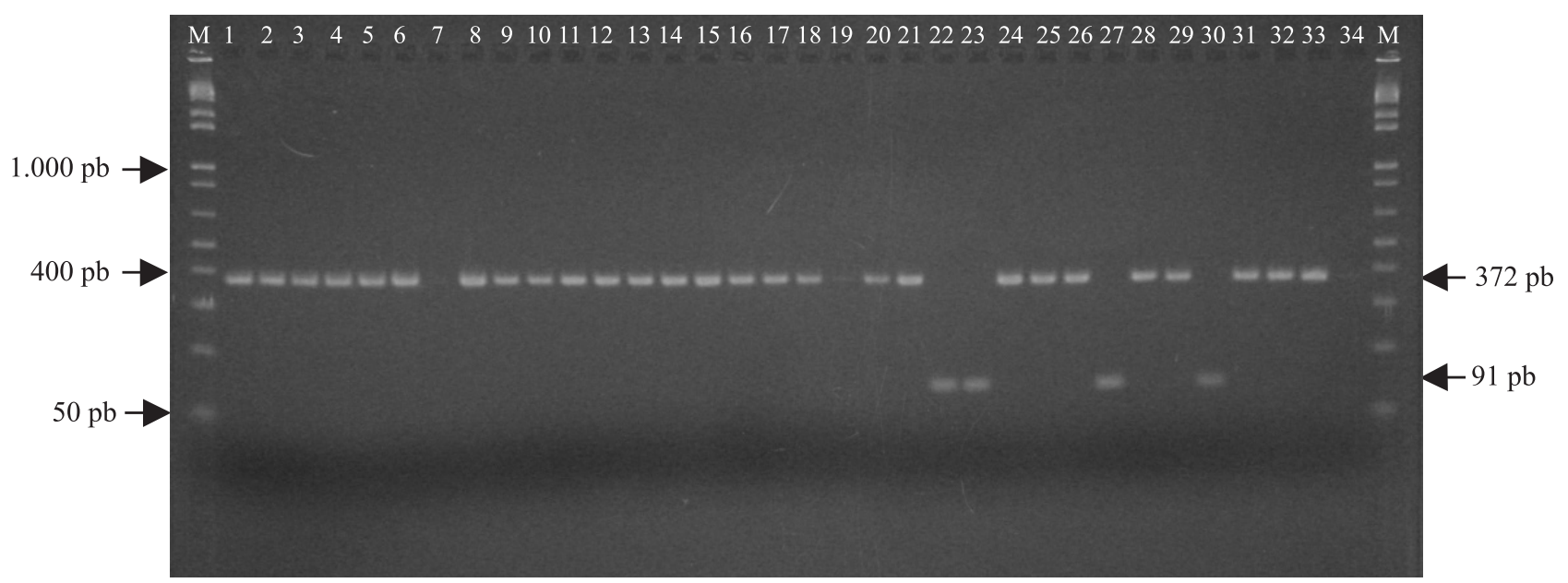

Figura 1. Amostras resultantes da amplificação com a série Mus, para determinação dos filotipos. Ordem das amostras: 1, TC01-06; 2, TC01-01; 3, TC01-08; 4, TC01-25; 5, TC01-09; 6, TC01-29; 7, TC01-18; 8, TC01-05; 9, TC01-26; 10, TC01-17; 11, TC01-45; 12, TC01-42; 13, TC01-43; 14, TC01-44; 15, TC01-02; 16, TC02-01; 17, TC02-02; 18, TC02-03; 19, ТC02-04; 20, TC03-02; 21, TC03-03; 22, TC03-04; 23, TC03-05; 24, TC03-06; 25, TC04-01; 26, TC04-02; 27, TC04-03; 28, TC05-01; 29, TC05-02; 30, TC05-03; 31, TC06-01; 32, TC06-02; 33, TC07-01; e 34, controle negativo; M, marcador $1 \mathrm{~kb}$ plus (Invitrogen Life Technologies, Carlsbad, CA, USA). Setas à esquerda indicam o tamanho dos fragmentos do marcador, e setas à direita indicam o tamanho dos fragmentos amplificados.

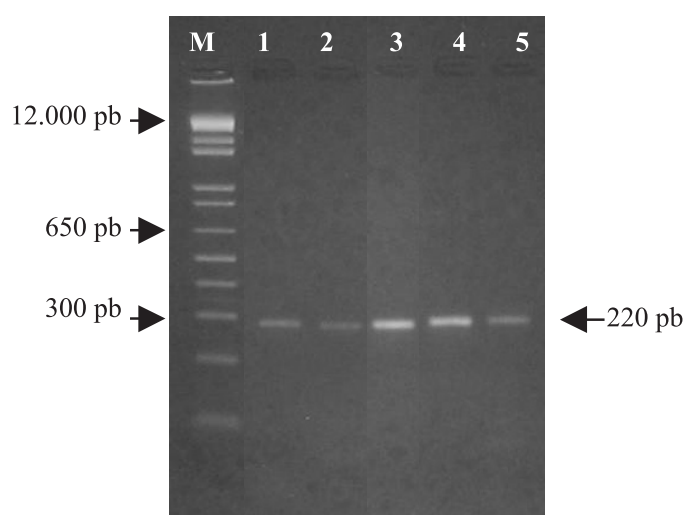

Figura 2. Perfil eletroforético das amostras resultantes da amplificação de oligonucleotídeos marcadores da série Nmult, para a determinação das sequevares (gel parcial). $\mathrm{M}$, Marcador $1 \mathrm{~kb}$ DNA plus (Invitrogen Life Technologies, Carlsbad, CA, USA); 1, TC02-02; 2, TC02-03; 3, TC02-01; $4, \mathrm{TC} 04-01 ; 5, \mathrm{TC} 04-02$. Setas à esquerda indicam o tamanho dos fragmentos do marcador, e setas à direita indicam o tamanho dos fragmentos amplificados.

Resultados semelhantes foram obtidos por Cardozo et al. 2009, em que a avaliação de 50 isolados permitiu a identificação de somente 35 isolados quanto à sequevar. Fegan \& Prior (2005) não obtiveram a identificação das sequevares de dois isolados brasileiros de banana, o que sugere, nesse caso, que os isolados brasileiros de banana provavelmente pertencem a uma sequevar ainda não determinada, como confirma esse estudo.

O perfil eletroforético gerado pela amplificação por rep-PCR das sequências repetitivas dos 33 isolados resultou em 18 fragmentos, com o iniciador ERIC, 11 fragmentos, com o iniciador REP, e oito fragmentos com o iniciador BOX (Figura 3). Os dados foram analisados isoladamente (REP, ERIC e BOX) e em conjunto (rep-PCR).

A análise do dendrograma do iniciador ERIC mostrou a formação de três grupos (G1, G2 e G3) com $19 \%$ de similaridade, dos quais dois grupos (G2 e G3) apresentaram apenas isolados pertencentes à raça 2 , e o outro grupo (G1) concentrou os isolados pertencentes à raça 1 (Figura $4 \mathrm{~A}$ ). Resultados semelhantes foram obtidos por Bringel et al. (2004), que agruparam os isolados patogênicos à berinjela com uso do iniciador ERIC. Apesar de $R$. solanacearum ser uma espécie altamente heterogênea e complexa, a utilização de rep-PCR para estudos de diversidade tem mostrado uma forte relação com o hospedeiro (Horita \& Tsuchiya, 2001; Kumar et al., 2004; Norman et al., 2009), explicada pelo alto grau de conservação evolucionária desses elementos repetitivos. 
Com o iniciador REP foi possível observar a formação de quatro grupos (G1, G2, G3 e G4) com $21 \%$ de similaridade, dos quais três foram mistos, compreenderam isolados pertencentes tanto à raça 1 quanto à raça $2 \mathrm{e}$ não mostraram perfil de agrupamento significativo para essa característica (Figura 4 B). Entretanto, foi possível visualizar um agrupamento, com $80 \%$ de similaridade dos quatro isolados (G4.1: TC03-04, TC03-05, TC04-03 e TC05-03), pertencente ao filotipo III, relacionado ao Continente Africano. Bringel et al. (2004) também encontrou correlação entre grupos de isolados e local de origem. Esses resultados não são frequentes na literatura com a utilização de rep-PCR, principalmente quando o agrupamento ocorre em microrregiões onde a bactéria tem habilidade de se adaptar rapidamente, por meio de mecanismos como transferência horizontal (Guidot et al., 2009) de genes capazes de conferir características adaptativas e, provavelmente, com correlação maior
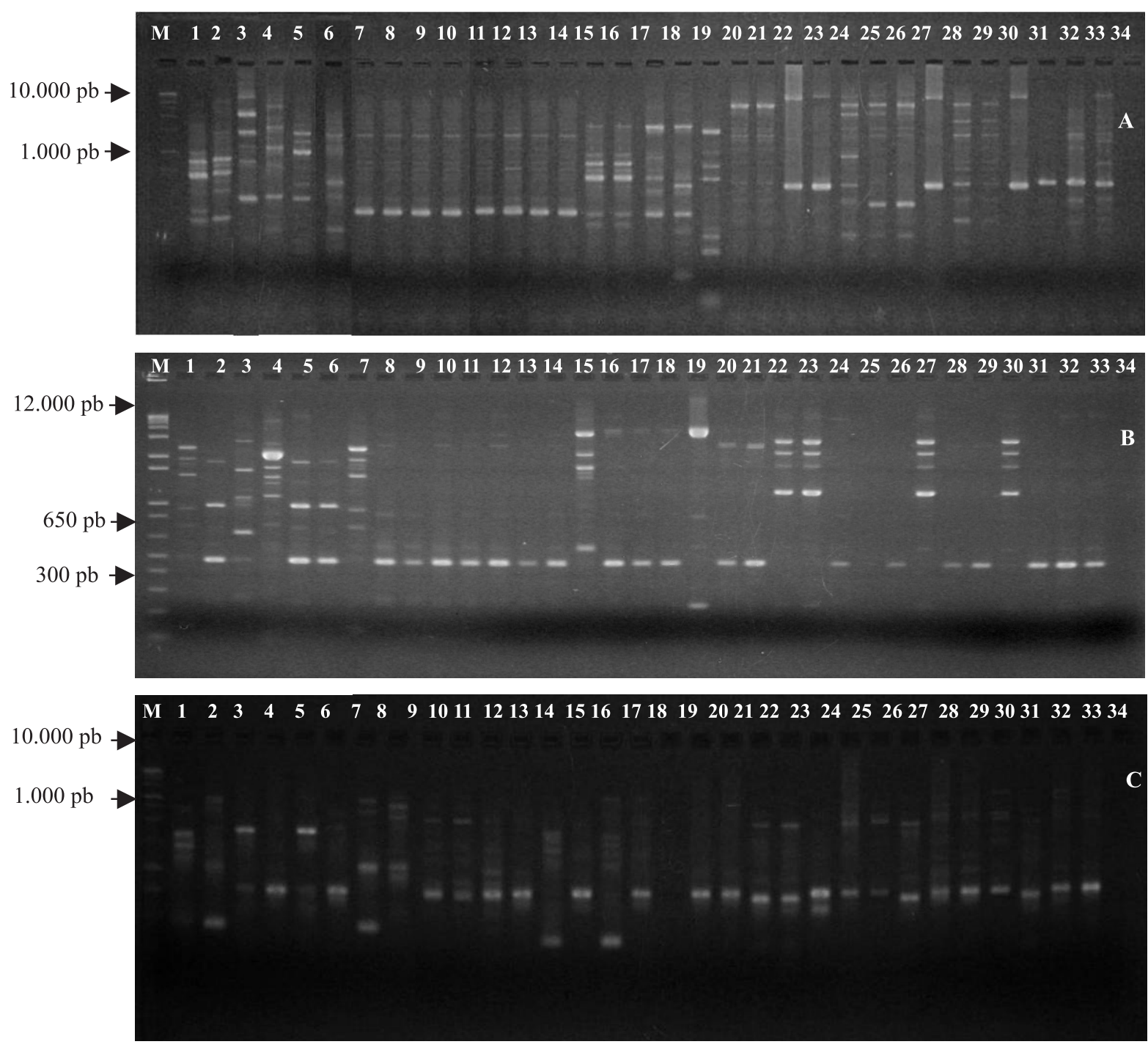

Figura 3. Perfis eletroforéticos obtidos pelos produtos da amplificação do DNA genômico de Ralstonia solanacearum com o uso dos marcadores ERIC-PCR (A), REP-PCR (B) e BOX-PCR (C). 1, TC01-06; 2, TC01-01; 3, TC01-08; 4, TC01-25; 5, TC01-09; 6, TC01-29; 7, TC01-18; 8, TC01-05; 9, TC01-26; 10, TC01-17; 11, TC01-45; 12, TC01-42; 13, TC01-43; 14, TC01-44; 15, TC01-02; 16, TC02-01; 17, TC02-02; 18, TC02-03; 19, TC02-04; 20, TC03-02; 21, TC03-03; 22, ТC03-04; 23, ТC03-05; 24, ТC03-06; 25, ТC04-01; 26, TC04-02; 27, TC04-03; 28, TC05-01; 29, TC05-02; 30, TC05-03; 31, TC06-01; 32, TC06-02; 33, TC07-01; e 34, controle negativo. Setas à esquerda indicam o tamanho dos fragmentos do marcador. 


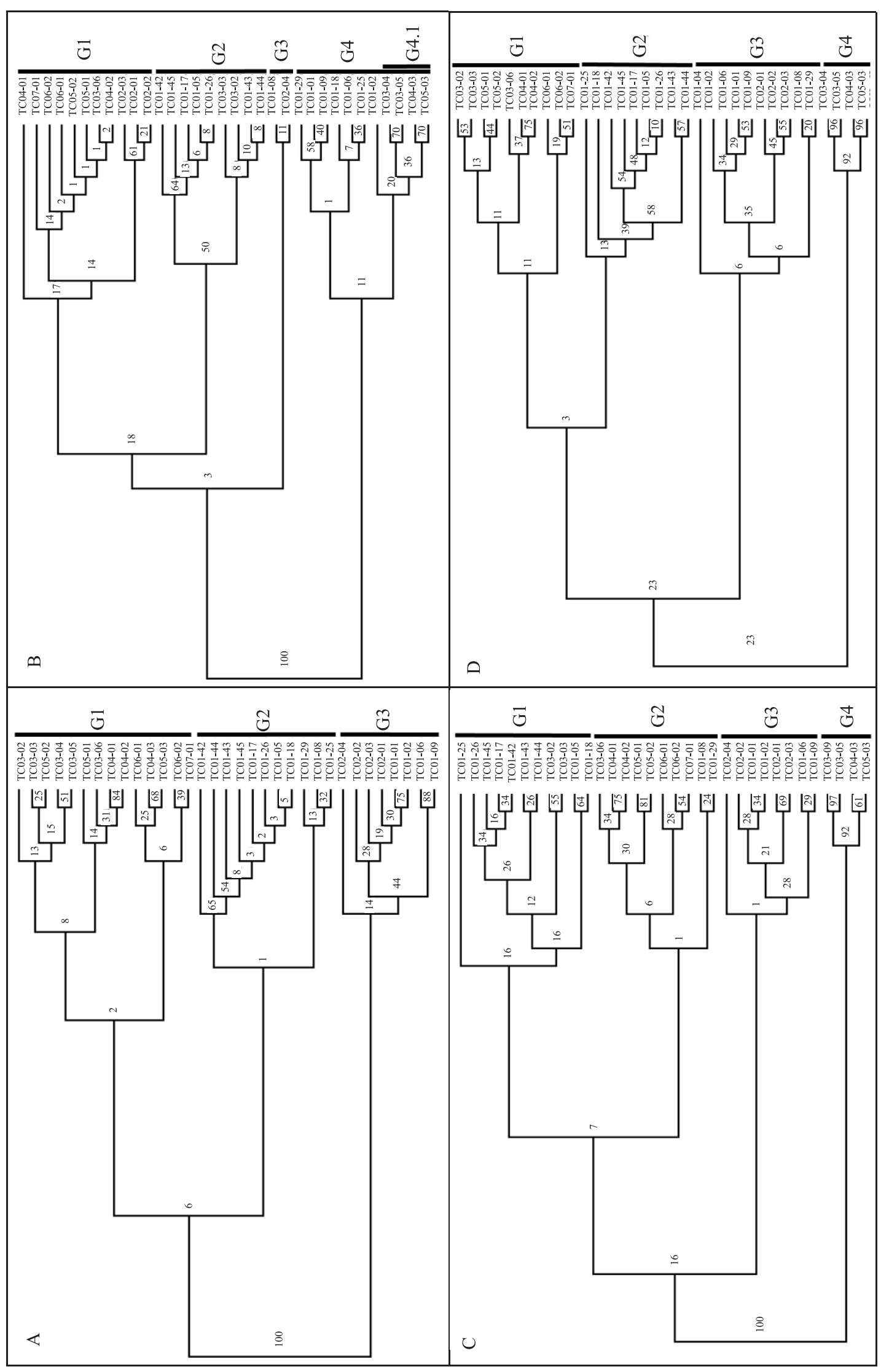

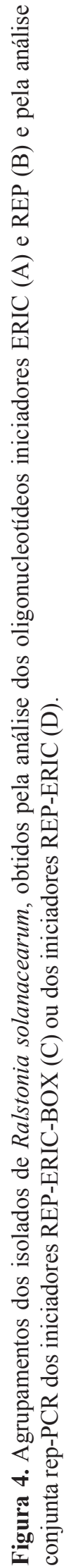


com outros tipos de marcadores moleculares, como o RAPD, por exemplo.

Para o iniciador BOX, não houve nenhuma correlação dos grupos formados com as características dos isolados analisadas neste estudo, como raça, biovar, filotipo, sequevar ou mesmo região geográfica. Este resultado, provavelmente, decorreu do baixo número de fragmentos amplificados; entretanto, outros estudos relatam que o sucesso e a utilidade dessa sequência repetitiva tem sido variável. Costa et al. (2007) usaram apenas o iniciador BOX para analisar a diversidade genética de isolados de $R$. solanacearum, patogênicos a tomate e outras hospedeiras, na Amazônia, e encontraram um alto grau de polimorfismo, sem que tenha sido possível, no entanto, correlacionar grupos genômicos com origem, biovar ou local de coleta. Resultados diferentes foram obtidos por Silveira et al. (2005), que diferenciaram as biovares 1 e 2 de isolados patogênicos à batata com uso dos iniciadores ERIC e BOX.

A análise conjunta de rep-PCR permitiu a identificação de quatro grupos (Figura 4 C), a 15\% de similaridade. Embora com o uso da análise conjunta tenha havido melhor separação entre os isolados pertencentes ao filotipo III e os demais, a clara separação observada com o iniciador ERIC entre os isolados pertencentes à raça 1 e os pertencentes à raça 2 não se manteve, tendo ocorrido a formação de dois grupos mistos, um grupo com isolados da raça 1 apenas, e outro com isolados da raça 2 .

A fim de verificar a influência do iniciador BOX - o único que não permitiu constatar alguma relação entre os grupos -, analisou-se o dendrograma apenas com os dados de REP e ERIC-PCR (Figura 4 D). A análise do dendrograma mostrou a formação de dois grupos maiores, em que os isolados pertencentes ao filotipo III formaram um grupo geneticamente distante dos demais. É interessante observar que o iniciador ERIC contribuiu para a melhor definição do agrupamento dos isolados pertencentes ao filotipo III.

Os 27 iniciadores RAPD geraram o total de 231 fragmentos polimórficos (média de 8,5 fragmentos por iniciador), o que mostra a alta diversidade genética dos isolados avaliados. A análise do dendrograma (Figura 5) permitiu a visualização de 11 grupos, dos quais seis só contêm isolados provenientes do Amazonas (G1, G2, G3, G7, G8 e G9), dois com isolados de Sergipe (G4 e G5) e, nos outros três grupos, não houve separação por região geográfica. Essa relação entre

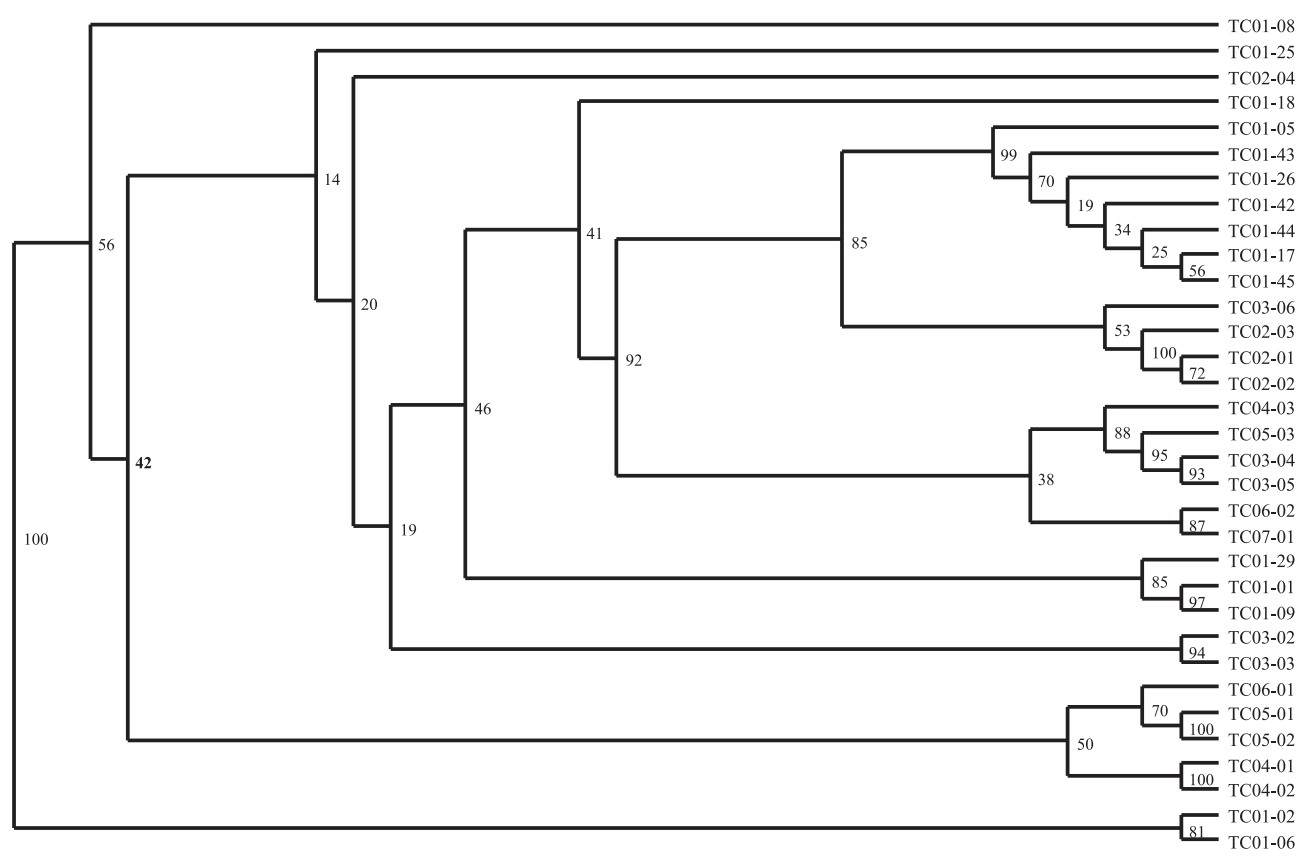

Figura 5. Análise de agrupamento dos isolados de Ralstonia solanacearum obtido por iniciadores RAPD. 
marcadores RAPD e grupos relacionados com sua origem geográfica tem sido relatada em outros trabalhos (Thwaites et al., 1999; Silveira et al., 2005).

\section{Conclusões}

1. A metodologia utilizada não permite caracterizar a grande maioria dos isolados avaliados de Ralstonia solanacearum quanto à sequevar, e os isolados de banana provavelmente pertencem a uma sequevar ainda não determinada.

2. A análise conjunta de sequências repetitivas de DNA, amplificadas com os iniciadores REP e ERIC, permite melhor separação dos isolados de $R$. solanacearum pertencentes ao filotipo III dos demais.

3. A raça 2 de $R$. solanacearum não está relacionada a nenhum dos marcadores RAPD utilizados.

\section{Referências}

ADDINSOFT. XLSTAT: your data analysis solution. Paris: Addinsoft, 2010. Disponível em: $<$ http://www.xlstat.com/>. Acesso em: 22 jul. 2010.

ARAHAL, D.R.; LLOP, P.; ALONSO, M.; LÓPEZ, M.M. In silico evaluation of molecular probes for detection and identification of Ralstonia solanacearum and Clavibacter michiganensis subsp. sepedonicus. Systematic and Applied Microbiology, v.27, p.581-591, 2004.

BRINGEL, J.M.; BEDENDO, I.; GUIMARÃES, P.M.; LOPES, C.A. Genetic diversity of Ralstonia solanacearum biovar 2 isolates of potato and eggplant from Brazil by PCR. Summa Phytopathologica, v.30, p.350-355, 2004.

CARDOZO, C.; RODRÍGUEZ, P.; MARÍN, M. Molecular characterization of the /Ralstonia solanacearum/ species complex in the banana growing region of Uraba. Agronomía Colombiana, v.27, p.203-210, 2009.

COSTA, S.B.; FERREIRA, M.A.S.V.; LOPES, C.A. Diversidade patogênica e molecular de Ralstonia solanacearum da Região Amazônica brasileira. Fitopatologia Brasileira, v.32, p.285-294, 2007.

COUPAT, B.; CHAUMEILLE-DOLE, F.; FALL, S.; PRIOR, P.; SIMONET, P.; NESME, X.; BERTOLLA, F. Natural transformation in the Ralstonia solanacearum species complex: number and size of DNA that can be transferred. FEMS Microbiology Ecology, v.66, p.14-24, 2008.

FEGAN, M.; PRIOR, P. How complex is the Ralstonia solanacearum species complex? In: ALLEN, C.; PRIOR, P.; HAYWARD, A.C. (Ed.). Bacterial wilt disease and the Ralstonia solanacearum species complex. St. Paul: American Phytopathological Society, 2005. p.449-461.
GUIDOT, A.; COUPAT, B.; FALL, S.; PRIOR, P.; BERTOLLA, F. Horizontal gene transfer between Ralstonia solanacearum strains detected by comparative genomic hybridization on microarrays. ISME Journal, v.3, p.549-562, 2009.

GUIDOT A.; PRIOR, P.; SCHOENFELD, J.; CARRÈRE, S.; GENIN, S.; BOUCHER, C. Genomic structure and phylogeny of the plant pathogen Ralstonia solanacearum inferred from gene distribution analysis. Journal of Bacteriology, v.189, p.377-387, 2007.

HAYWARD, A.C. The hosts of Pseudomonas solanacearum. In: HAYWARD, A.C.; HARTMAN, G.L. (Ed.). Bacterial wilt: the disease and the causative agent, Pseudomonas solanacearum. Willingford: CAB International, 1994. p.9-24.

HE, L.Y.; SEQUEIRA, L.; KELMAN, A. Characteristics of strains of Pseudomonas solanacearum from China. Plant Disease, v.67, p.1357-1361, 1983.

HORITA, M.; TSUCHIYA, K. Genetic diversity of Japanese strains of Ralstonia solanacearum. Phytopathology, v.91, p.399-407, 2001.

KUMAR, A.; SARMA, Y.R.; ANANDARAJ, M. Evaluation of genetic diversity of Ralstonia solanacearum causing bacterial wilt of ginger using REP-PCR and PCR-RFLP. Current Science, v.87, p.1555-1561, 2004.

NORMAN, D.J.; ZAPATA, M.; GABRIEL, D.W.; DUAN, Y.P.; YUEN, J.M.F.; MANGRAVITA-NOVO, A.; DONAHOO, R.S. Genetic diversity and host range variation of Ralstonia solanacearum strains entering North America. Phytopathology, v.99, p.1070-1077, 2009.

PAVLÍCEK, A.; HRDÁ, S.; FLEGR, J. FreeTree - freeware program for construction of phylogenetic trees on the basis of distance data and bootstrap/jackknife analyses of the tree robustness. Application in the RAPD analysis of the genus Frenkelia. Folia Biologica, v.45, p.97-99, 1999.

PRIOR, P.; FEGAN, M. Recent developments in the phylogeny and classification of Ralstonia solanacearum. Acta Horticulturae, n.695, p.127-136, 2005.

SALANOUBAT, M.; GENIN, S.; ARTIGUENAVE, F.; GOUZY, J.; MANGENOT, S.; ARLAT, M.; BILLAULT, A.; BROTTIER, P.; CAMUS, J.C.; CATTOLICO, L.; CHANDLER, M.; CHOISNE, N.; CLAUDEL-RENARD, C.; CUNNAC, S.; DEMANGE, N.; GASPIN, C.; LAVIE, M.; MOISAN, A.; ROBERT, C.; SAURIN, W.; SCHIEX, T.; SIGUIER, P.; THEBAULT, P.; WHALEN, M.; WINCKER, P.; LEVY, M.; WEISSENBACH, J.; BOUCHER, C.A. Genome sequence of the plant pathogen Ralstonia solanacearum. Nature, v.415, p.497-502, 2002.

SAMBROOK, J.; RUSSELL D.W. Molecular cloning: a laboratory manual. New York: Cold Spring Harbor Laboratory, 2001. Irregular paging.

SEAL, S.E.; JACKSON, L.A.; DANIELS, M.J. Use of tRNA consensus primers to indicate subgroups of Pseudomonas solanacearum by polymerase chain reaction amplification. Applied and Environmental Microbiology, v.58, p.3759-3761, 1992. 
SEAL, S.E.; JACKSON, L.A.; YOUNG, J.P.W.; DANIELS, M.J. Differentiation of Pseudomonas solanacearum, Pseudomonas syzygii, Pseudomonas pickettii and the Blood Disease bacterium by partial $16 \mathrm{~S}$ rRNA sequencing: construction of oligonucleotide primers for sensitive detection by polymerase chain reaction. Journal of General Microbiology, v.139, p.1587-1594, 1993.

SILVEIRA, J.R.P.; DUARTE, V.; MORAES, M.G.; OLIVEIRA, A.M.R.; BARNI, V.; MACIEL, J.L.N. Caracterização de estirpes de Ralstonia solanacearum isoladas de plantas de batata com murcha bacteriana por PCR-rep e RAPD. Fitopatologia Brasileira, v.30, p.615-622, 2005.
SNEATH, P.H.A.; SOKAL, R.R. Numerical taxonomy: the principles and practice of numerical classification. San Francisco: W.H. Freeman, 1973. 573p.

THWAITES, R.; MANSFIELD, J.; EDEN-GREEN, S.; SEAL, S. RAPD and rep PCR-based fingerprinting of vascular bacterial pathogens of Musa spp. Plant Pathology, v.48, p.121-128, 1999.

XU, J.; PAN, Z.C.; PRIOR, P.; XU, J.S.; ZHANG, Z.; ZHANG, H.; ZHANG, L.Q.; HE, L.Y.; FENG, J. Genetic diversity of Ralstonia solanacearum strains from China. European Journal of Plant Pathology, v.125, p.641-653, 2009.

Recebido em 1 de fevereiro de 2011 e aprovado em 5 de maio de 2011 